\title{
Stage-specific apoptosis, developmental delay, and embryonic lethality in mice homozygous for a targeted disruption in the murine Bloom's syndrome gene
}

\author{
Nicholas Chester, ${ }^{1,2}$ Frank Kuo, ${ }^{3}$ Christine Kozak, ${ }^{4}$ Cathie D. O'Hara, ${ }^{1,2}$ and Philip Leder ${ }^{1,2,5}$ \\ ${ }^{1}$ Howard Hughes Medical Institute, ${ }^{2}$ Department of Genetics, and ${ }^{3}$ Department of Pathology, Brigham and Women's \\ Hospital, Harvard Medical School, Boston, Massachusetts 02115 USA; ${ }^{4}$ National Institutes of Health, National Institute \\ of Allergy and Infectious Diseases, Bethesda, Maryland 20892-0460 USA
}

\begin{abstract}
Bloom's syndrome is a human autosomal genetic disorder characterized at the cellular level by genome instability and increased sister chomatid exchanges (SCEs). Clinical features of the disease include proportional dwarfism and a predisposition to develop a wide variety of malignancies. The human BLM gene has been cloned recently and encodes a DNA helicase. Mouse embryos homozygous for a targeted mutation in the murine Bloom's syndrome gene $(B / m)$ are developmentally delayed and die by embryonic day 13.5 . The fact that the interrupted gene is the homolog of the human BLM gene was confirmed by its homologous sequence, its chromosomal location, and by demonstrating high numbers of SCEs in cultured murine $\mathrm{Blm}^{-/-}$ fibroblasts. The proportional dwarfism seen in the human is consistent with the small size and developmental delay (12-24 hr) seen during mid-gestation in murine $\mathrm{Blm}^{-/-}$embryos. Interestingly, the growth retardation in mutant embryos can be accounted for by a wave of increased apoptosis in the epiblast restricted to early post-implantation embryogenesis. Mutant embryos do not survive past day 13.5 , and at this time exhibit severe anemia. Red blood cells and their precursors from $\mathrm{Blm}^{-/-}$embryos are heterogeneous in appearance and have increased numbers of macrocytes and micronuclei. Both the apoptotic wave and the appearance of micronuclei in red blood cells are likely cellular consequences of damaged DNA caused by effects on replicating or segregating chromosomes.
\end{abstract}

[Key Words: Bloom's syndrome; knockout mouse; genome instability; sister chromatid exchange; micronuclei; apoptosis]

Received July 24, 1998; revised version accepted September 15, 1998.

Bloom's syndrome (BS) is a rare recessive genetic disorder characterized by proportional dwarfism, telangiectatic erythema, immune deficiency, and an increased risk for all cancers (for review, see German 1993). The increased cancer risk is manifested by early appearance of leukemias, lymphomas, carcinomas, and rare tumors with a mean age of onset of 24.7 years (German 1997).

One of the defining features of the disease is the presence of chromosome aberrations in cultured Bloom's cells. Other genome instability syndromes such as Fanconi anemia, ataxia telangiectasia, and Werner syndrome, also have increased levels of chromosome gaps, breaks, and rearrangements (for review, see Arlett and Lehman 1978; Ray and German 1983; Therman and Susman 1993). Unique to Bloom's cells, are increased exchanges between homologous chromosomes, and in the presence of bromodeoxyuridine (BrdU), high numbers of

${ }^{5}$ Corresponding author.

E-MAIL Leder@Rascal.med.harvard.edu; FAX (617) 432-7944. sister chromatid exchanges (SCEs) are seen (Chaganti et al. 1974; for review, see German 1993). Increased and error-prone homologous recombination in somatic cells may represent a mechanism for mutation in BS (Groden et al. 1990; Groden and German 1992; German 1993). Evidence for increased somatic mutation comes from analysis of erythrocytes, in which the frequency of variants at the glycophorin A locus is increased 50- to 100fold; also, the rate of mutation at the HPRT locus in cultured fibroblasts is increased 10-fold (Warren et al. 1981; Vijayalaxmi et al. 1983; Kyoizumi et al. 1989; Langlois et al. 1989).

The gene for BS $(B L M)$ has been identified, and is a member of the RecQ subfamily of DExH box containing RNA and DNA helicases (Ellis et al. 1995). The human cDNA codes for a 1417 amino acid polypeptide that contains, in addition to seven conserved helicase domains, extended amino and carboxyl termini relative to the prototypical Escherichia coli RecQ and human RECQL DNA helicase family members (Ellis et al. 1995; Watt 
and Hickson 1996). The BLM protein is most similar to two other RecQ helicases, Saccaromyces cerevisiae Sgs1p and Schizosaccharomyces pombe Rqh1; all three contain the helicase homology region at a similar position, are similar in size, and contain two acidic amino acid clusters in the amino terminus (Gangloff et al. 1994; Watt et al. 1995; Stewart et al. 1997). The more recent cloning of the Werner syndrome gene (WRN) also identified it as a member of the RecQ helicase subfamily; the gene sequence predicts the WRN protein to be similar in size to BLM, containing one acidic domain in the amino terminus (Yu et al. 1996).

Recent biochemical analysis has shown that Sgs1p, WRN, and BLM are all active helicases with $3{ }^{\prime}-5^{\prime}$ DNAunwinding activity. (Lu et al. 1996; Gray et al. 1997; Karow et al. 1997). Analysis of BLM homologs in S. cerevisiae and $S$. pombe has provided clues to helicase function and has led to the identification of interacting cellular proteins. In $S$. pombe, $r q h 1^{-}$mutants arrest normally when treated with hydroxyurea; however, following recovery and cell cycle progression, exhibit defects in chromosome segregation in the following mitosis (Stewart et al. 1997). In addition to being necessary for recovery from S-phase arrest induced by hydroxyurea, $r q h 1^{+}$ acts to suppress chromosome instability and hyperrecombination (Stewart et al. 1997). In S. cerevisiae, sgs1 mutants exhibit hyperrecombination and chromosome mis-segregation (Watt et al. 1995, 1996). The SGS1 gene genetically interacts with the $S$. cerevisiae type I topoisomerases TOP1 and TOP3 (Gangloff et al. 1994; Lu et al. 1996). In addition, the Sgs1 polypeptide physically interacts with Top $2 \mathrm{p}$ and Top3p, the $S$. cerevisiae homologs of mammalian DNA topoisomerases II and III, respectively (Gangloff et al. 1994; Watt et al. 1995).

We made a mouse model for the human disease to gain insight into BLM function. We have found that mice homozygous for a targeted mutation in Blm die in utero. In this report, we correlate physiological and cellular features of the mouse Blm mutant and BS. Our analysis reveals that mutation of mouse $B l m$ has multiple consequences for both $B 1 \mathrm{~m}^{-/-}$embryos and cultured fibroblasts as the result of a severe cellular defect.

\section{Results}

\section{Genetic mapping of mouse Blm}

We isolated mouse genomic and cDNA clones homologous to human BLM (Ellis et al. 1995). Sequence analysis of a 1.1-kb clone obtained from a NIH-3T3 cDNA library showed $77 \%$ identity to a region spanning nucleotide residues 777-1844 in the human BLM cDNA sequence (Ellis et al. 1995; Materials and Methods). The putative Blm cDNA clone P-1 was mapped in the mouse genome to determine if it localized to a region syntenic to the human $B L M$ locus. P-1 identified variant fragments in strains Mus spretus and NFS/N by Southern blot analysis (Materials and Methods). The inheritance of the variant fragments was compared with inheritance of other markers. P-1 (Blm) maps to mouse chromosome 7 with the following gene order and recombination fractions

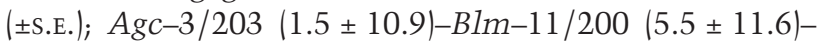
Tyr. Human BLM maps to chromosome 15q26.1; AGC1, the human homolog of mouse $A g c$ maps to $15 \mathrm{q} 26$. These data establish that the P-1 DNA fragment and the human $B L M$ gene map to regions of conserved synteny and confirms that both cDNA and genomic clones of the mouse homolog of human BLM had been isolated.

Targeted mutation of Blm in ES cells and generation of $\mathrm{Blm}^{+/-}$mice

A site upstream of the Blm helicase homology domain was targeted for disruption by use of homologous recombination in ES cells. The targeting vector containing the neomycin (neo) gene for positive selection and the thymidine kinase $(t k)$ gene for negative selection, was electroporated into 129/SvEv ES cells (Fig. 1A). By Southern blot analysis, 1 of 93 clones analyzed was determined to carry the targeted mutation (data not shown). Following transfer of ES clone cells into blastocysts, it was determined by crosses with NIH Black Swiss mice that most of the chimeras born transmitted the targeted mutation to the $\mathrm{F}_{1}$ generation. Heterozygous mice appear normal and are phenotypically indistinguishable from wild-type littermates until at least 1 year of age. Genotype analysis of $\mathrm{F}_{2}$ pups did not reveal animals homozygous for the targeted mutation. Initially, to determine whether mutant animals could be found, a litter of nine 17 day post coitum (dpc) embryos was dissected. Southern analysis was used on embryo genomic DNA and reveals the presence of one dead embryo that was homozygous for the mutant allele (Fig. 1B, 6 of 9 embryo DNAs are shown). Table 1 shows that of $329 \mathrm{~F}_{2}$ generation newborn mice genotyped to date, none were homozygous for the mutation. Therefore, in the outbred $129 / \mathrm{SvEv} \times \mathrm{NIH}$ Black Swiss background, $B \mathrm{~m}^{-/-}$mice have an embryonic lethal phenotype. In addition, chimeras were crossed to $129 /$ SvEv wild-type mice to produce animals with an inbred background; genotype evaluation of $\mathrm{F}_{2}$ animals has not revealed $\mathrm{Blm}^{-1-}$ mice (data not shown).

\section{Characterization of $\mathrm{Blm}^{-1-}$ embryos and analysis of Blm mRNA expression}

To characterize the developmental stage at which $B \mathrm{~m}^{-/-}$embryos die, staged embryos from heterozygous matings were obtained. Table 1 shows the genotype frequency in percent for all embryos, and for each stage examined, approximate Mendelian segregation of the mutant Blm allele is observed. At $14.5 \mathrm{dpc}$ or later, $7 / 7$ mutant embryos were dead, at $13.5 \mathrm{dpc}, 15$ of 35 mutant embryos were alive. All stages examined prior to 13.5 dpc show a high percentage of live mutant embryos (Table 1). This analysis suggests that mutant embryos do not survive past $13.5 \mathrm{dpc}$.

To extend our analysis of $B 1 \mathrm{~m}^{-/-}$embryo lethality, we were interested in determining whether the Blm mRNA 
Chester et al.

A
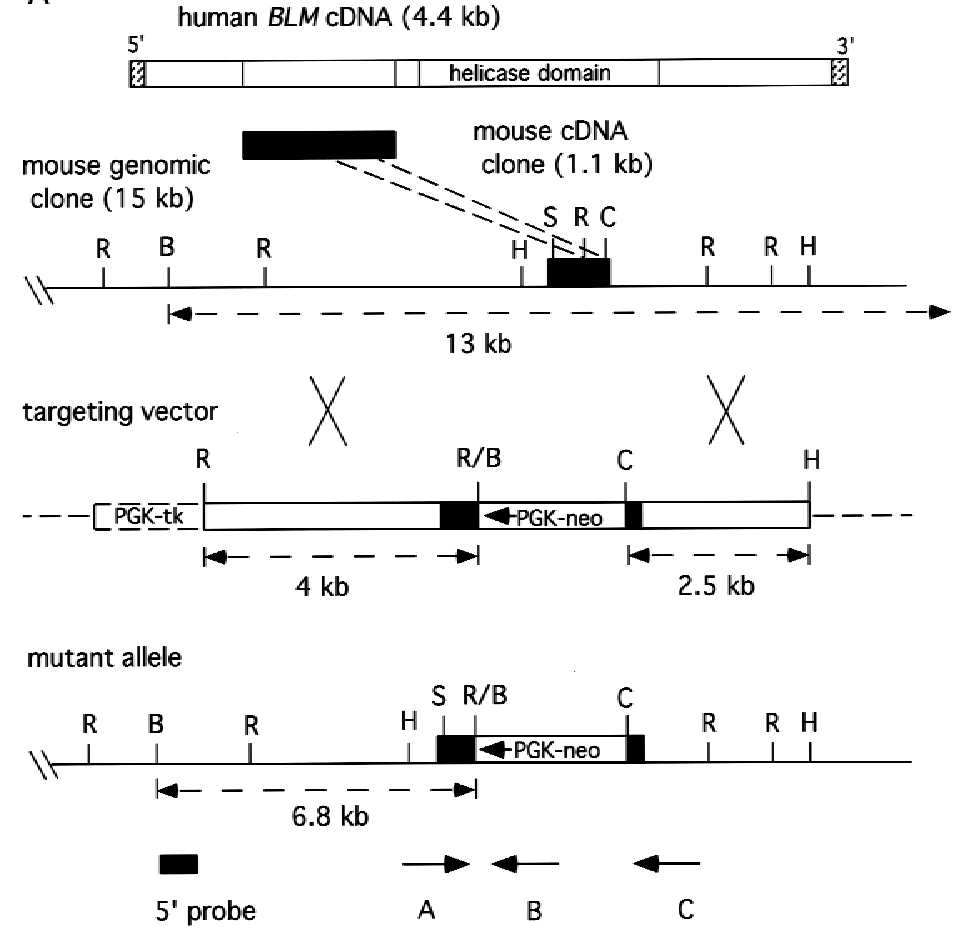

B

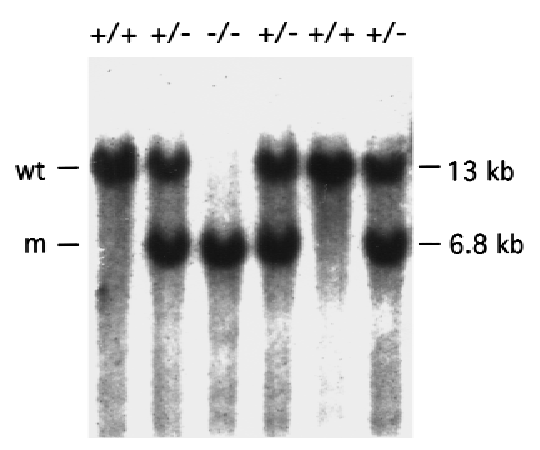

C

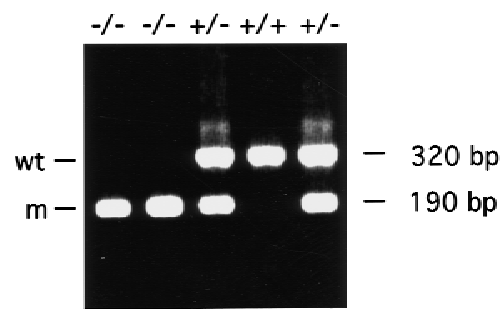

Figure 1. Targeted disruption of the mouse Blm gene. $(A)$ Shown is the alignment of the mouse Blm cDNA fragment upstream of the helicase domain present in the human BLM coding sequence. The map of mouse Blm genomic clone DNA is shown with restriction sites and the targeted coding region indicated by black shading. (B) BamHI; (C) ClaI; (H) HindIII; (R) EcoRI; (S) StuI. The targeting vector contained the neo resistance and the herpes simplex virus tk genes under the control of the mouse PGK promoter. Homologous recombination resulted in deletion of $180 \mathrm{bp}$ of sequence between the EcoRI and ClaI sites and placed the direction of transcription of PGK-neo opposite that of Blm in the mutant allele. A Blm gene $5^{\prime}$-flanking probe used for screening ES cell clones and mice is indicated; also the predicted sizes of wild-type and mutant fragments that resulted from restriction digestion of genomic DNA with BamHI are shown. Positions of oligonucleotide primers used for PCR genotype analysis are indicated (A, B, and C). (B) Southern blot analysis of BamHI-digested embryo genomic DNA. Fragments that hybridized to the $5^{\prime}$ probe are $13 \mathrm{~kb}$ for the wild-type allele (wt) and $6.8 \mathrm{~kb}$ for the mutant allele $(\mathrm{m}) .(C)$ PCR analysis of embryo yolk sac genomic DNA. With the simultaneous addition of three oligonucleotide primers to the $\mathrm{PCR}$, all possible genotypes can be obtained. Reaction products that resulted from primer pair $\mathrm{AB}$; 190-bp mutant allele (m), and primer pair AC; 320-bp wild-type allele (wt), are visualized by agarose gel electrophoresis and ethidium bromide staining. Genotypes are shown at top for each assay in $B$ and $C$.

transcript was expressed during normal embryonic development. Northern blot analysis of RNA purified from staged wild-type embryos shows the presence of a single 4.4-kb transcript expressed from stages 9.5-13.5, and $16.5 \mathrm{dpc}$ (Fig. 2A). To examine the effect of the PGK-neo cassette on $B l m$ transcription, mRNA was purified from proliferating postcrisis $B 1 \mathrm{~m}^{+/+}$and $B \mathrm{~mm}^{-/-}$mouse embryonic fibroblasts (MEFs) and analyzed by Northern blot (Materials and Methods). The 4.4-kb Blm transcript is present in wild type, but not in mutant MEFs, which instead contain several faint transcripts of altered mobility (Fig. 2C, arrow and asterisks). Our results indicate that expression of Blm during embryogenesis is required for embryo viability.

We extended our analysis of Blm expression to tissues from wild-type adult mice. Expression of a single Blm transcript is seen in most tissues examined, and is highest in spleen, thymus, ovary, and testis (Fig. 2E, arrow). Interestingly, in testis in which expression is greatest, another transcript of slightly slower mobility is seen
(Fig. 2E, TE'). Expression of Blm may reflect a role for the gene product in mitotic and meiotic recombination.

\section{Mutant Blm embryos exhibit a developmental delay phenotype}

To further evaluate defects in $B 1 \mathrm{~m}^{-/-}$embryos, the morphology of whole embryos was analyzed. At $9.5 \mathrm{dpc}$, $B \mathrm{~m}^{+/+}$and $B \mathrm{~m}^{+/-}$embryos appear similar in size and development; in contrast, two mutant $\mathrm{Blm}^{-/-}$littermates are smaller in size by $\sim 50 \%$ and are developmentally delayed (Fig. 3A). At 10.5 dpc, a mutant embryo is reduced in size and exhibits delay relative to a heterozygous littermate (Fig. 3B). Likewise, evaluation of later stages of development shows similarity in size and development for pairs of mutants obtained from 11.5- and 12.5-dpc litters (Fig. 3C,D). The trend of small size and developmental delay in $B 1 \mathrm{~m}^{-1-}$ embryos persists to the time of death at $13.5 \mathrm{dpc}$ (Fig. 3F). Morphologic evaluation of $\mathrm{Blm}^{-/-}$embryos during dissection shows that 
Table 1. Genotype of offspring from $\mathrm{Blm}^{+/-} \times \mathrm{Blm}^{+/-}$matings

\begin{tabular}{|c|c|c|c|c|}
\hline Age (dpc) & $+/+$ & $+1-$ & $-/-$ & $\begin{array}{c}\text { Status of } \\
\text { mutant } \\
\text { embryos }\end{array}$ \\
\hline 9.5 & $15(30 \%)$ & $27(54 \%)$ & $8(16 \%)$ & 8 alive \\
\hline 10.5 & $36(26 \%)$ & $80(57 \%)$ & $24(17 \%)$ & $\begin{array}{l}20 \text { alive, } \\
2 \text { dead, } \\
2 \text { uk }\end{array}$ \\
\hline 11.5 & $29(25 \%)$ & $62(53 \%)$ & $26(22 \%)$ & $\begin{array}{l}24 \text { alive, } \\
1 \text { dead, } \\
1 \text { uk }\end{array}$ \\
\hline 12.5 & $25(21 \%)$ & $69(58 \%)$ & $25(21 \%)$ & $\begin{array}{l}17 \text { alive, } \\
7 \text { dead, } \\
1 \text { uk }\end{array}$ \\
\hline 13.5 & $38(22 \%)$ & $102(58 \%)$ & $35(20 \%)$ & $\begin{array}{l}15 \text { alive, } \\
19 \text { dead, } \\
1 \text { uk }\end{array}$ \\
\hline$\geqslant 14.5$ & $8(24 \%)$ & $18(55 \%)$ & $7(21 \%)$ & 7 dead \\
\hline Newborn & $104(32 \%)$ & $225(68 \%)$ & 0 & \\
\hline
\end{tabular}

a Status of mutant embryos: alive, presence of heartbeat; dead, no heartbeat, and in more advanced cases, blood coagulation and tissue necrosis was observed. Cases where the embryo appeared viable, but heartbeat was absent are defined as unknown (uk).

they are remarkably normal in their own body proportions and orientation. The developmental hallmarks such as number of somites, formation of limb buds, presence of otic and optic vesicles, appearance of liver bud, and development of the heart and placenta all exhibit a similar rate of delay. We estimate that Blm mutants have a uniform and constant developmental delay of 0.51.0 day from 9.5 to 13.5 dpc (Fig. 3A-F).

Histology on sections obtained from fixed embryos was performed. Examination of hematoxylin and eosin stained sagittal sections of 9.5-13.5-dpc Blm ${ }^{-/-}$embryos showed that the heart, the great vessels, the microcirculation, liver bud, the developing neural tube, craniofacial structures, and somites, all appear normal except for developmental delay (data not shown). Histological sections of Blm embryos dissected with the yolk sac, umbilical cord, and placenta intact showed that the extraembryonic membranes, including the developing placenta, although smaller, all appear normal in mutants from 10.5 to $12.5 \mathrm{dpc}$ (data not shown).

The status of mutant embryos around the time of death was evaluated (Table 1). Following dissection that left the yolk sac and placenta intact, comparison of 13.5-dpc $\mathrm{Blm}^{-/-}$embryos with normal littermates reveals a relative lack of blood circulating through the fetus and the yolk sac vessels (Fig. 3E). The mutant embryos exhibit paleness both prior to and after removal of the yolk sac (Fig. 3E,F). Bleeding from the umbilical vessels also revealed a marked reduction of the blood volume and the number of circulating red blood cells beginning at $9.5 \mathrm{dpc}$. Apart from severe anemia, embryos between 12.5 and 13.5 dpc did not show any other morphologic change suggestive of any tissue or organ-specific cause of death.

\section{Red blood cells from $\mathrm{Blm}^{-/-}$embryos have aberrant morphology and increased numbers of micronuclei}

Although reduced in number, blood islands are seen in the mutant yolk sac at various stages of development. Additionally, histological examination of 10.5- and 11.5dpc mutant liver sections indicates the presence of erythropoiesis, suggesting that progression to adult stage hematopoiesis in the liver has taken place normally in the mutant embryos (data not shown).

To further evaluate the nature of the anemia in $\mathrm{Blm}^{-/-}$ embryos, Wright-Giemsa-stained blood smears were made from bleeding through the umbilical vessels of embryos from 9.5 to 13.5 dpc. Examination of the smears showed that at $12.5 \mathrm{dpc}$, mutant embryos have both fetal and adult-type erythroid cells at various stages of maturation. However, there is a marked decrease in both the volume of blood and the number of red cell progenitors

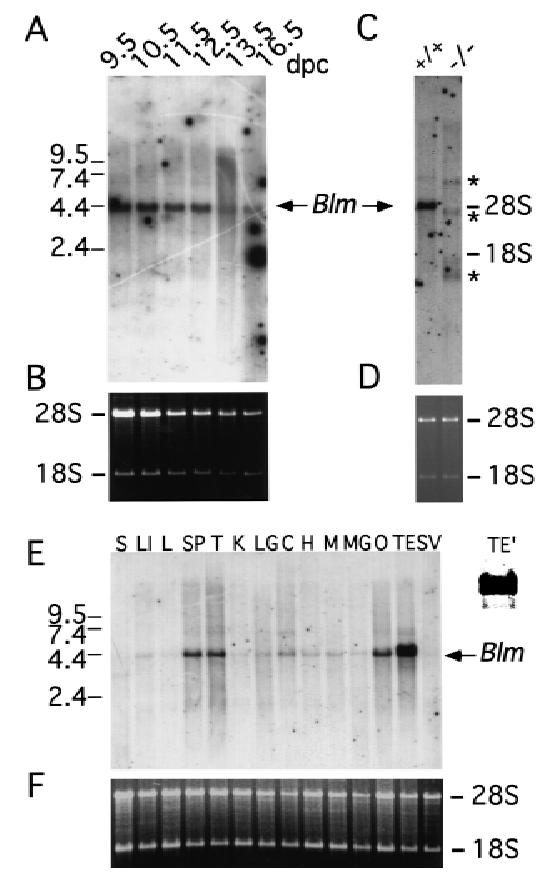

Figure 2. Northern blot analysis of embryo, embryonic fibroblast, and adult tissue RNA. (A) RNA analysis of Blm expression during embryonic development. Poly(A) RNA was prepared from 9.5 to 13.5 and 16.5 dpc wild-type embryos; lanes are indicated at top. $(C)$ RNA blot analysis of Blm expression in MEFs. Poly(A) RNA from $\mathrm{Blm}^{+/+}$or $\mathrm{Blm}^{-/-}$embryonic fibroblasts; genotype is indicated at top. Aberrant transcripts that appear in the $B 1 \mathrm{~m}^{-/-}$fibroblast lane are indicated $\left.{ }^{\star}\right)$. (E) RNA blot of Blm expression in mouse organs. Poly(A) RNA was prepared from tissues of adult FVB mice; lanes are indicated at top: (S) Stomach; (LI) large intestine; (L) liver; (SP) spleen; (T) thymus; (K) kidney; (LG) lung; (C) cerebrum; (H) heart; (M) muscle; (MG) mammary gland; $(\mathrm{O})$ ovary; (TE) testis; (SV) seminal vesicle. In testis, an additional higher molecular weight transcript is seen $\left(\mathrm{TE}^{\prime}\right) .(A, C, E)$ The 4.4-kb Blm transcript is indicated (arrow). $(B, D, F)$ For quantitation of lane loading, the ethidium bromidestained gel is shown for comparison. The $28 \mathrm{~S}$ and $18 \mathrm{~S}$ RNAs are indicated. RNA molecular mass markers are in $\mathrm{kb}$ for $A$ and $E$, the positions of $28 \mathrm{~S}$ and $18 \mathrm{~S}$ RNAs are shown in $C$. 

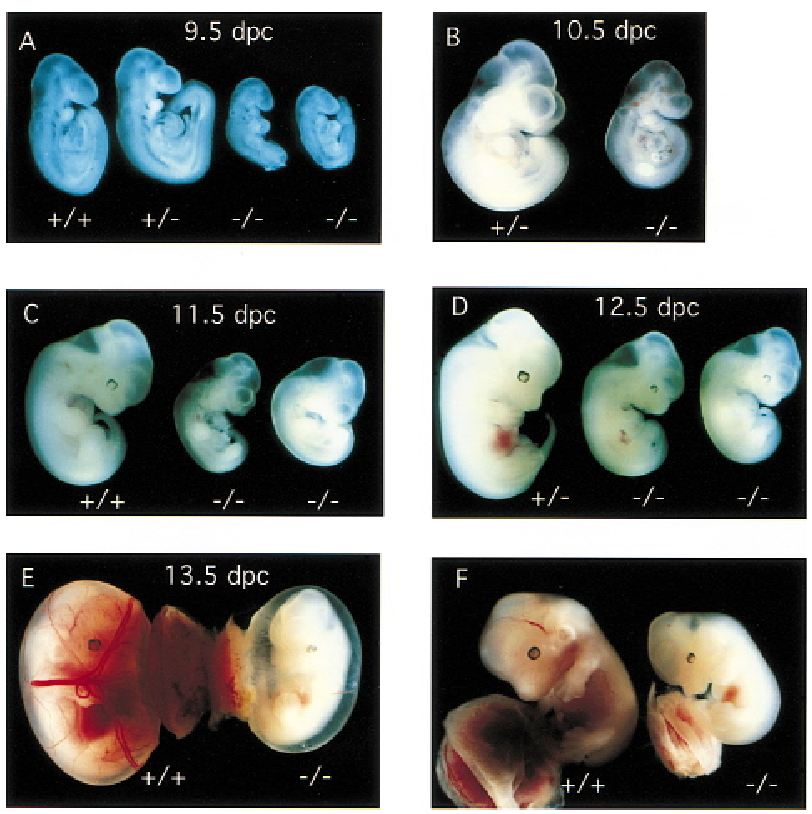

Figure 3. $B \mathrm{Im}^{-/-}$embryos exhibit small size and developmental delay. (A) $9.5 \mathrm{dpc}$ a pair of normal $\left(B \mathrm{Bm}^{+/+}\right.$and $\left.B \mathrm{~mm}^{+/-}\right) \mathrm{em}-$ bryos are compared with two $B 1 \mathrm{~m}^{-/-}$embryo littermates. $(B)$ $10.5 \mathrm{dpc}$; comparison of $\mathrm{Blm}^{+/-}$and $B 1 \mathrm{~m}^{-/-}$embryo littermates. $(C, D)$ Normal 11.5-dpc Blm ${ }^{+/+}$and 12.5-dpc Blm ${ }^{+/-}$embryos are compared with pairs of mutant $B 1 \mathrm{~m}^{-/-}$littermates. $(E)$ Comparison of 13.5 -dpc $B 1 \mathrm{~m}^{+/+}$embryos with a mutant $B 1 \mathrm{~m}^{-/-}$littermate with intact yolk sac and placenta. $(F)$ The same pair of embryos shown in $E$ with yolk sacs removed. Embryos in $A$ were photographed in $70 \%$ ethanol after fixation in $4 \%$ paraformaldehyde in PBS. Embryos in $(B-F)$ were photographed at the time of dissection. At dissection, embryos were determined to be alive on the basis of the presence of a heartbeat.

and matured red cells $\left(\mathrm{Blm}^{-/-}\right.$embryos had $5 \%-10 \%$ as much blood as their wild-type littermates at $12.5 \mathrm{dpc}$. Additionally, there is a wide variation of cell size, with increased numbers of macrocytes and an increased presence of nuclear fragments in mutant versus wild-type erythrocytes for two pairs of representative $12.5-\mathrm{dpc}$ embryo littermates (Fig. 4A-D).

We were interested in quantifying nuclear fragments or micronuclei in red blood cells and their precursors from Blm embryos. We used the DNA-specific Feulgen reaction that has been used previously to detect micronuclei in exfoliated cells from Bloom's patients (Rosin and German 1985). Following Feulgen reaction and fast green stain of embryo sections, red blood cells and their precursors from the heart and major vessels were scored for the presence of micronuclei. Micronuclei appear as a characteristic single, smaller purple-staining body appearing outside the main nucleus (Fig. 4E,F). Sometimes variation in size and multiple micronuclei are observed. We scored numbers of blood cells containing micronuclei from 9.5 to $13.5 \mathrm{dpc}$. The incidence of mutant cells containing micronuclei varies from $8 \%$ to $12 \%$, and in normal cells from $0.3 \%$ to $1.4 \%$ (Fig. $4 \mathrm{G}$; error bars are indicated). Increased numbers of micronuclei provide evidence for chromosome defects occurring during cell division in $\mathrm{Blm}^{-/-}$nucleated red blood cells and their progenitors. Micronuclei form around damaged or lagging chromosomes that result from an aberrant mitosis (Therman and Susman 1993). The possiblity that other cell types in Blm mutant embryos might contain micronuclei is currently under investigation. Recently, we have found increased numbers of micronuclei in primary cultures of $\mathrm{Blm}^{-/-}$embryonic fibroblasts (data not shown).

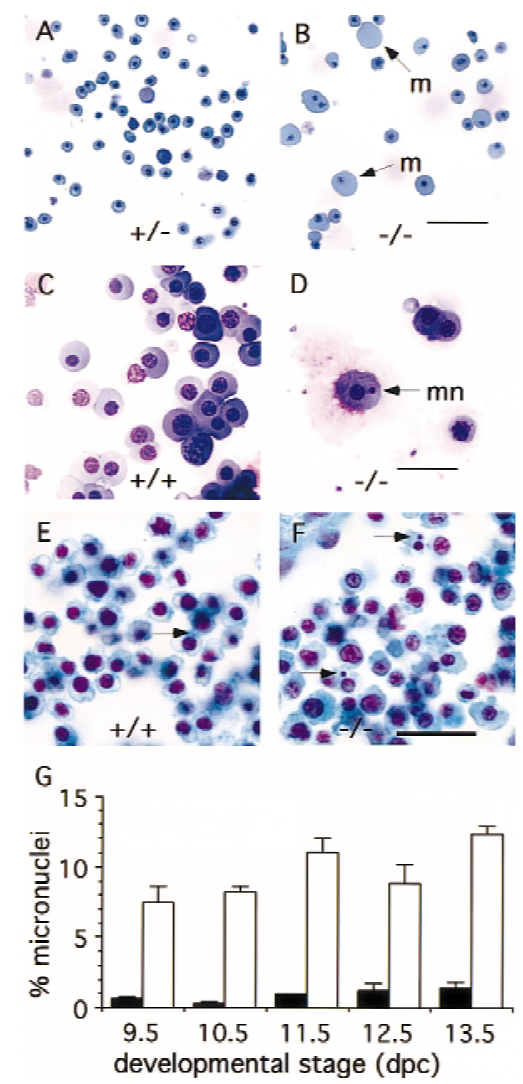

Figure 4. Defective red blood cell production in Blm mutant embryos. $(A, B)$ Wright-Giemsa stain of umbilical bleeds obtained from a pair of 12.5-dpc embryos, shown are red blood cells and their progenitors from $\mathrm{Blm}^{+/-}$or $\mathrm{Blm}^{-/-}$littermates, respectively. (B) Arrows point to macrocytes $(\mathrm{m})$. $(C, D)$ WrightGiemsa stain of umbilical bleeds obtained from another pair of normal and mutant 12.5-dpc littermates. $(D)$ Next to the main nucleus, a cell also contains a smaller micronucleus, arrow $(\mathrm{mn}) .(E, F)$ Feulgen reaction and fast green stain of 11.5-dpc embryo red blood cells and their progenitors; shown are positive staining micronuclei from $\mathrm{Blm}^{+/+}$or $\mathrm{Blm}^{-/-}$embryos, respectively. (E) A $B 1 \mathrm{~m}^{+/+}$cell with a micronucleus is seen (arrow). ( $F$ ) Two $B 1 \mathrm{~m}^{-1-}$ cells have a micronucleus (arrows). $(A, B)$ Size bar, $60 \mu \mathrm{M} ;(C-F)$ size bar $25 \mu \mathrm{M}$. The genotype is indicated at bottom. $(G)$ Numbers of micronuclei in Blm embryo blood cells. For stages 9.5-13.5 dpc, two normal and two mutant embryos were scored for the presence of micronuclei by Feulgen reaction and fast green stain of embryo sections. For each embryo, 500 nucleated red blood cells and their precursors were scored in the major vessels and heart. Average values are shown for two normal or two mutant embryos (solid bars and open bars, respectively). Error bars, average deviations from the mean. 
Increased apoptosis in the epiblast of early postimplantation $\mathrm{Blm}^{-/-}$embryos

To examine more closely the phenomenon of small size and developmental delay in $\mathrm{Blm}{ }^{-/-}$embryos, histological analysis was performed on sections of early postimplantation embryos. Embryo sections were subjected to genotype analysis prior to processing for histology (Materials and Methods). The numbers of embryos evaluated were (developmental stage, mutants/total); $6.0 \mathrm{dpc}$, 8/29; $6.5 \mathrm{dpc}, 16 / 50 ; 7.0 \mathrm{dpc}, 5 / 15 ; 7.5 \mathrm{dpc}, 14 / 38$; and $8.0 \mathrm{dpc}, 5 / 16$. Evaluation of a representative pair of early egg cylinder-stage embryos shows a $6.0-\mathrm{dpc} B 1 \mathrm{~m}^{-/-}$embryo that is similar in size and development to a $\mathrm{Blm}^{+/+}$ littermate, with both showing comparable development of the epiblast and extraembryonic region (Fig. 5A,B). In contrast, a 6.5-dpc mutant is smaller in size, and exhibits both a reduced epiblast and extraembryonic region relative to a normal heterozygous littermate (Fig. 5C,D). At $6.5 \mathrm{dpc}$, the mutant fails to exhibit mesoderm formation, which is seen in the normal embryo (Fig. 5C). The trend in defective growth is seen at $7.5 \mathrm{dpc}$, at which a $\mathrm{Blm}$ mutant is smaller in size, and exhibits less well-developed mesoderm, epiblast, and extraembryonic region relative to that seen in a normal littermate (Fig. 5E,F). Analysis of an 8.0-dpc Blm ${ }^{+/-}$embryo section shows a well-developed extraembryonic region, an advanced primitive streak, and early head fold formation (Fig. 5G). In contrast, a $B \mathrm{~m}^{-/-}$littermate is much smaller, has a less well-developed epiblast and extraembryonic region, but does form a primitive streak (Fig. $5 \mathrm{H}$ ).

To pursue the possibility that increased apoptosis might be occurring in Blm mutant embryos, end-labeling of nucleosome fragments with digoxigenin-UTP by the TUNEL assay was performed on 7.5-dpc embryo sections. Evaluation of a $\mathrm{Blm}^{+/-}$section reveals the presence of apoptotic debris in the amniotic cavity (Fig. 5E). In contrast, a section from a $B \mathrm{~lm}^{-/-}$littermate exhibits a large number of apoptotic cells in the epiblast and amniotic cavity; interestingly, there appear to be relatively few apoptotic cells in the extraembryonic region (Fig. 5F). Comparable numbers and distribution of apoptotic cells were seen in three other 7.5-dpc mutant sections analyzed by TUNEL assay (data not shown).

Feulgen reaction and fast green-stained embryo sections were scored for apoptotic figures in normal and mutant embryos. For 6.0-, 6.5-, 7.0-, 7.5-, and 8.0-dpc embryo sections, the epiblast was scored, and for 9.5- and 11.5-dpc sections, neuroectoderm was scored. At 6.0 dpc, the index (frequency) of pyknotic nuclei is similar for normal and mutant embryos, respectively (Fig. 6A). However, at $6.5 \mathrm{dpc}$, the normal embryo index is $7 \%$, whereas the mutant embryo index has increased to $26 \%$. Likewise, large differences in apoptosis are observed at 7.0, 7.5, and $8.0 \mathrm{dpc}$ (Fig. 6A). In contrast, at 9.5 or 11.5 $\mathrm{dpc}$, the mutant apoptotic index decreases substantially, mutant and normal indices are $1 \%$ and $3 \%$ for each stage, respectively (Fig. 6A; error bars are indicated). The data shown here indicates that increased apoptosis occurs in Blm mutant embryos during a restricted period of development ranging from 6.5 to at least $8.0 \mathrm{dpc}$. Because of the level of embryo differentiation at later stages of development, the epiblast was not relevant for the scoring assay. Because of the simultaneous presence of apoptotic and mitotic figures, neuroectoderm was scored at developmental stages of 9.5 or $11.5 \mathrm{dpc}$. On the basis of
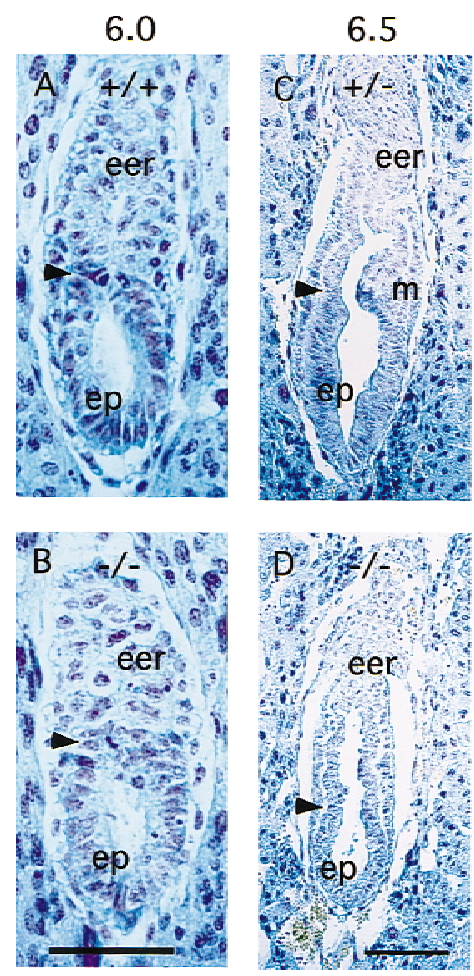

7.5
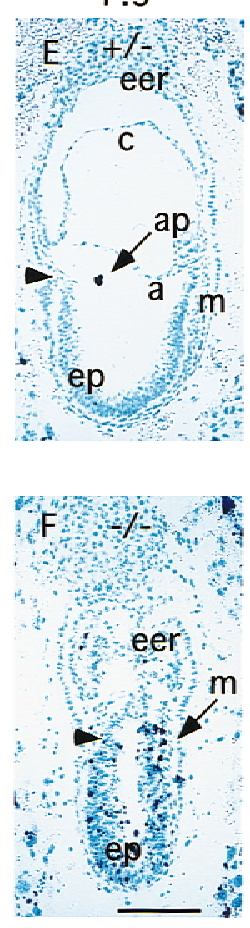

$8.0 \mathrm{dpc}$
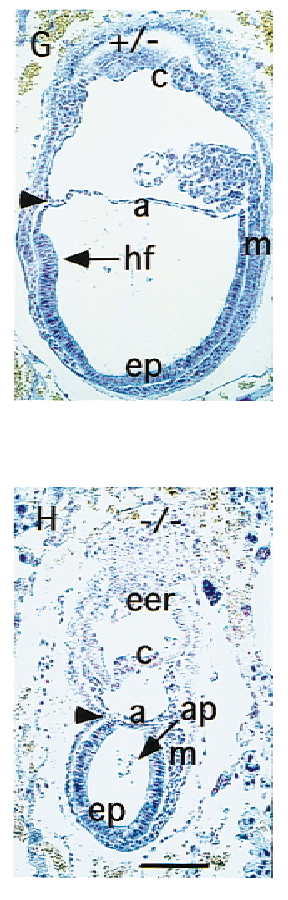

Figure 5. Defective development in Blm mutant embryos. Histological analysis was performed on embryo sections stained with Feulgen and fast green $(A-D, G, H)$ or methyl green $(E, F)$. Each pair of panels represent embryos derived from the same litter; developmental stage is indicated (top). $(A, B)$ 6.0-dpc early egg cylinder stage of $B \mathrm{~m}^{+/+}$and $B 1 \mathrm{~m}^{-1-}$ embryos, respectively. $(C, D) 6.5$-dpc gastrulation stage of $B \mathrm{Bm}^{+/-}$and $B 1 \mathrm{~m}^{-/-}$embryos, respectively. (E) TUNEL assay of a $7.5-\mathrm{dpc} B 1 \mathrm{~m}^{+/-}$ embryo; apoptotic debris is indicated (ap, arrow). (F) TUNEL assay of a 7.5-dpc $\mathrm{Blm}^{-/-}$embryo; black apoptotic nuclei appear throughout the epiblast. $(G, H)$ Early organogenesis stage of $8.0-\mathrm{dpc} \mathrm{Blm}^{+/-}$ and $\mathrm{Blm}^{-/-}$embryos, respectively. Apoptotic debris is observed in the amniotic cavity of the mutant $[(H)$ ap, arrow]. (Arrowheads) Separation between the extraembryonic and embryonic region. (a) amnion; (c) chorion; (eer) extraembryonic region; (ep) epiblast; (hf) headfold; (m) mesoderm. Size bar, $60 \mu \mathrm{M}$ in $A$ and $B ; 120 \mu \mathrm{M}$ in $C-F ; 250 \mu \mathrm{M}$ in $G$ and $F$. 


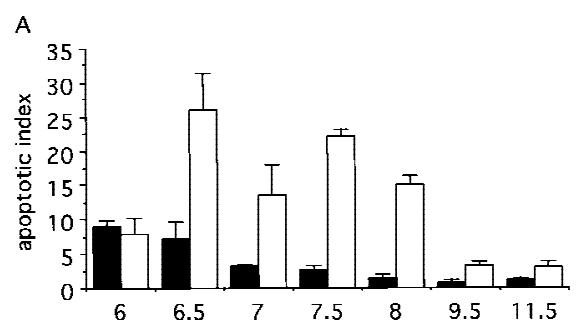

B

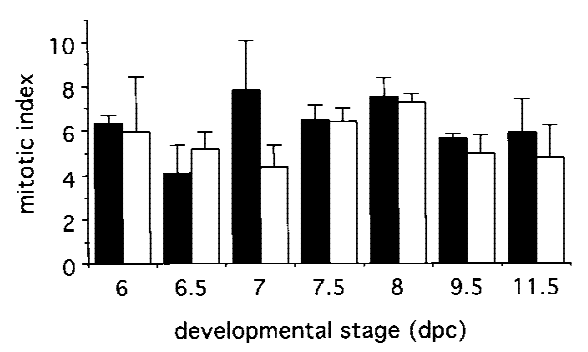

Figure 6. Analysis of apoptosis and mitosis in Blm mutant embryos. For 6.0-, 6.5-, 7.0-, 7.5-, and 8.0-dpc embryos, Feulgenpositive pyknotic nuclei, or mitotic figures, divided by the total number of cells scored in the epiblast, yield the apoptotic $(A)$ or mitotic $(B)$ index, respectively. For 9.5- and 11.5-dpc embryos, neuroectoderm was scored. For each embryo, two adjacent $5 \mu \mathrm{M}$ sections were counted and the average value obtained. Equal numbers of normal and mutant embryos were evaluated at each developmental stage, for 6.0, 6.5, 7.5, 8.0, 9.5, $11.5 \mathrm{dpc}(N=6)$ and $7.0 \mathrm{dpc}(N=8)$. Bars, average values for normal or mutant embryos (solid bars and open bars, respectively). Error bars, average deviations from the mean.

Feulgen stain or TUNEL analysis, apoptosis in other tissue types does not appear to be substantially elevated in mutant versus normal embryos at 9.5 or $11.5 \mathrm{dpc}$, or during other later developmental stages (data not shown).

To extend our analysis on $B 1 \mathrm{~m}^{-/-}$embryo cells, the same embryo sections that were scored for apoptosis were scored for mitotic figures. From 6.0 to $11.5 \mathrm{dpc}$, for normal and mutant embryos, the mitotic index ranged from $4 \%$ to $8 \%$, and no significant differences are seen between the two (Fig. 6B, error bars are indicated). Analysis of BrdU incorporation was performed on normal and mutant embryos at 6.5 or $7.5 \mathrm{dpc}$. No significant differences were observed in the ability of normal and mutant embryos to incorporate the thymidine analog (data not shown). These data suggest that significant blocks do not occur in either $S$ or $M$ phases of the cell cycle during early embryogenesis. Therefore, early post-implantation $\mathrm{Blm}^{-/-}$embryos undergo net cell loss due exclusively to excessive apoptosis.

The developmental stages in which small size and developmental delay first occur correlate with the increase in apoptosis (cf. Figs. 5, C-H, and 6A). During later development from $9.5 \mathrm{dpc}$ to the time of death around $13.5 \mathrm{dpc}$, apoptosis in Blm mutants is much reduced (Fig. 6A). Therefore, we propose that the growth deficit observed in later stage mutant embryos is caused by a wave of excessive apoptosis that is restricted to early embryogenesis.
Retarded growth of primary $\mathrm{Blm}^{-/-}$embryonic fibroblasts

We evaluated the growth characteristics of primary MEFs derived from mutant embryos. Human Bloom's fibroblasts grow slowly in culture and undergo premature senescence (Giannelli et al. 1977; Warren et al. 1981; Willis and Lindahl 1987). Initial efforts to propagate $B \mathrm{~lm}^{-/-}$MEFs in culture in medium containing fetal calf serum were largely unsuccessful. Relative to cultures derived from wild type and heterozygote embryos, mutant fibroblasts either failed to proliferate, or grew slowly, and often did not survive passage (data not shown). However, we have found that if embryos are sufficiently developmentally advanced, the larger size results in a cell number sufficient to seed a culture capable of growing for several passages. Growth curve analysis was conducted on passage 3 cultures derived from 12.5or 13.5-dpc mutant embryos and normal littermates. The mutant culture obtained from a 12.5 -dpc embryo fails to proliferate during the time course, whereas the heterozygous cells divide readily. Cultures derived from 13.5dpc embryos show a similar trend, with much reduced proliferation of mutant versus wild-type cells (Fig. 7A). However, in contrast to the culture derived from the 12.5-dpc mutant, the 13.5-dpc mutant culture did exhibit a limited degree of proliferation. Likewise, the 13.5dpc $B 1 \mathrm{~m}^{+/+}$embryo culture shows greater proliferation than cells derived from the 12.5 -dpc $\mathrm{Blm}^{+/}$embryo (Fig. 7A). In two other growth curve experiments, separate litters yielded pairs of $B \mathrm{~mm}^{+/-}$and $\mathrm{Blm}^{+/+}$embryo littermates. MEFS derived from these embryos grew with normal and similar kinetics (data not shown). Therefore, the enhanced proliferation of cultures derived from later stage embryos is likely dependent on an increased cell seeding number at passage 0 .

We have seen that by passage 4 or 5 , normal MEFs slow in growth and will enter crisis at that time, or soon thereafter. On occasion, cultures of cells in crisis have become overgrown because of emergence of variants capable of continued growth. The properties that our MEF cultures exhibit of undergoing crisis at early passage followed by recovery through progression to immortalization have been described (Todaro and Green 1963; Campisi 1996). To assay relative growth rates of established postcrisis cell lines, growth curve analysis was conducted on two $\mathrm{Blm}^{-/-}$mutant fibroblast lines with $\mathrm{Blm}^{+/+}$and $B \mathrm{Bm}^{+/-}$clones included for comparison. Three lines consisting of mutant, wild-type, and heterozygous clones, grow with essentially identical kinetics and contact inhibit at similar cell densities (Fig. 7B). A second mutant line grows at a high rate after initial slow growth and, at the end of the experiment, has a greater cell number and rate of growth than the three other clones (Fig. 7B; clone 8301-2). We have obtained four postcrisis mutant lines including the two assayed in Figure 7B. During passage, all mutant lines grow rapidly relative to the parental primary cultures /data not shown). The different growth properties exhibited by clone 8301-2 may provide the exception to the growth 
A

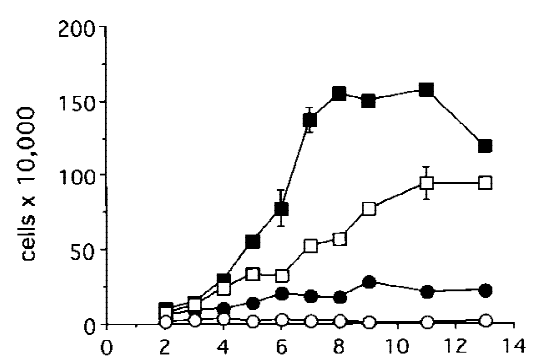

B

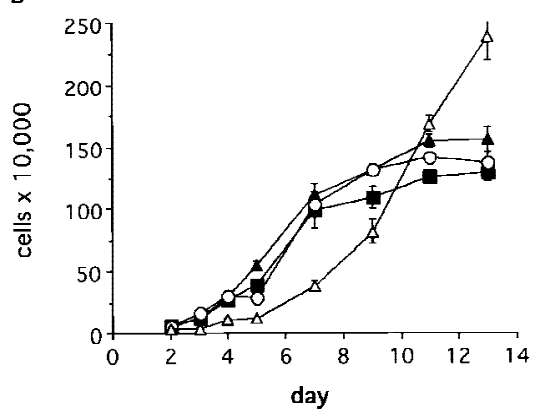

Figure 7. Retarded growth of primary $\mathrm{Blm}^{-1-}$ embryonic fibroblasts. The proliferation rates of low passage mutant cultures in $A$ are compared with those of later passage postcrisis lines in $B$. (A) Growth curve on passage 3 embryonic fibroblasts consisting of a pair of cultures derived from $13.5-\mathrm{dpc} \mathrm{Blm}^{+/+}(\mathbf{\square})$ and $\mathrm{Blm}^{-/-}$

(O) Blm embryos and a pair of cultures derived from 12.5-dpc $\mathrm{Blm}^{+/-}(\square)$ and $B \mathrm{~mm}^{-/-}(\mathrm{O})$ embryos. Each time point is represented by the average of cell counts from duplicate wells; error bars represent the range between values. $(B)$ Growth curve on postcrisis cell lines that varied in passage number from 9 to 11 , consisting of wild-type, heterozygous, and two mutant clones, generated as described in Materials and Methods. Clone desig-

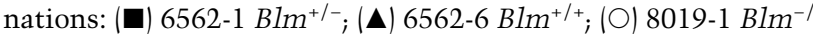
$-;(\triangle)$ 8301-2 $\mathrm{Blm}^{-1-}$. Growth rates are evaluated in similar fashion to cultures in $A$. The cell lines in $B$ are derived independently of the cultures shown in $A$.

characteristics of the mutant fibroblast lines generated to date. In conclusion, poor growth of primary $\mathrm{Blm}^{-/-}$ fibroblasts is abrogated when cultures escape cellular senescence.
Blm mutant embryonic fibroblasts have increased numbers of SCES

Fibroblasts and lymphoblastoid cells from BS patients have been shown to exhibit 10- to 15-fold higher numbers of SCEs relative to normal controls /Chaganti et al. 1974; Heartlein et al. 1987; for review, see German 1993). To determine if cells from $\mathrm{Blm}^{-/-}$embryos recapitulate this aspect of the human phenotype, we evaluated numbers of SCEs in MEFs. For this analysis, immortal fibroblast cell lines were used. The same four postcrisis cell lines used for growth curve analysis (Fig. 7B) were used in the assay and varied in passage number from 8 to 17 . We obtained metaphases that contained chromosomes with differentially stained sister chromatids (Materials and Methods). Examination of a $\mathrm{Blm}^{+/+}$ metaphase shows few chromosomes that exhibit exchanges between sister chromatids (Fig. 8A). In contrast, a metaphase from a mutant $B 1 \mathrm{~m}^{-1-}$ cell line shows a large increase in SCEs. Most chromosomes exhibit multiple exchanges between sister chromatids, producing a striking harlequin chromosomes effect (Fig. 8B).

To quantitate the level of SCEs present in each cell line, 15 metaphases were scored for both chromosome number and number of SCEs. The mean chromosome number and the mean number of SCEs for each cell line is shown in Table 2. Therefore, to obtain standardized values, exchanges were expressed as number of SCEs/ chromosome for each cell line. The mean number of SCEs/chromosome \pm S.D. obtained in wild-type and heterozygous clones 6562-6 and 6562-1, is $0.20 \pm 0.07$ and $0.25 \pm 0.08$, respectively (Table 2 ). In contrast, metaphases from mutant clones 8301-2 and 8019-1, yielded average values of $1.44 \pm 0.32$ and $1.08 \pm 0.16$ SCEs/chromosome, respectively (Table 2). These results show that mutation of Blm is sufficient to cause the high SCE phenotype characteristic of BS cells.

\section{Discussion}

On the basis of the human Bloom's phenotype, we expected to obtain live mice homozygous for a targeted disruption in Blm. Some evidence exists for intrauterine

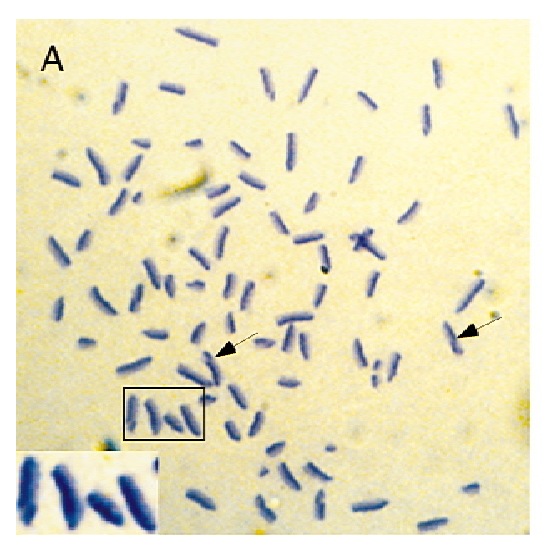

$+/+$

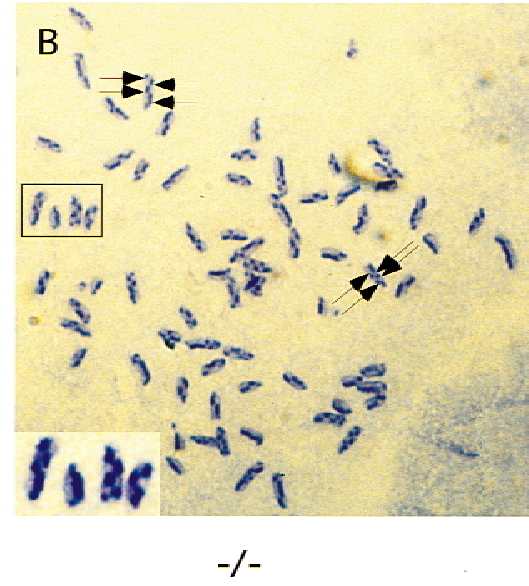

Figure 8. Evaluation of SCEs in Blm embryonic fibroblasts. $(A, B)$ Metaphase spreads of differentially stained chromosomes. Each chromosome consists of a pair of sister chromatids; one stains light, the other dark purple. (A) Metaphase from a $B 1 \mathrm{~m}^{+/+}$fibroblast cell line. Two chromosomes in which exchanges between sister chromatids have occurred are indicated (arrows). (B) Metaphase from a $\mathrm{Blm}^{-/-}$cell line. Most chromosomes exhibit multiple SCEs, producing a checkerboard pattern of alternating staining between sister chromatids. Two chromosomes with multiple SCEs (arrows) are indicated. $(A, B)$ Insets with enlarged chromosomes are magnified from the indicated rectangles. 
Table 2. Summary of sister chromatid exchanges in MEFS

\begin{tabular}{lcccc}
\hline Cell line & $\begin{array}{c}\text { No. of } \\
\text { metaphases }\end{array}$ & $\begin{array}{c}\text { Mean no. of } \\
\text { chromosomes }\end{array}$ & $\begin{array}{c}\text { Mean no. of } \\
\text { SCEs/metaphase }\end{array}$ & Mean no. of SCEs/chromosome \\
\hline $6562-6(+/+)$ & 15 & $67.6(40-82)$ & $13.4(3-20)$ & $0.20 \pm 0.07(0.08-0.40)$ \\
$6562-1(+/-)$ & 15 & $39.4(34-41)$ & $9.8(8-20)$ & $0.25 \pm 0.08(0.14-0.37)$ \\
$8301-2(-/-)$ & 15 & $52.7(39-74)$ & $75.8(38-141)$ & $1.44 \pm 0.32(0.93-2.04)$ \\
$8019-1(-/-)$ & 15 & $69.3(60-77)$ & $75.1(60-95)$ & $1.08 \pm 0.16(0.87-1.36)$ \\
\hline
\end{tabular}

Ranges are indicated in parentheses; \pm indicates S.D.

lethality in humans. The proportion of Bloom's individuals is less than expected for transmission of an autosomal recessive trait (German 1969). Consistent with abnormal reduced birth weight, fetal lethality in humans has been proposed to occur as a function of diminishing fetal mass (German 1969). In BS, patients that are homozygous for nonsense and frameshift mutations aminoterminal of the helicase domain have been identified (Ellis et al. 1995). In addition, immunoblot analysis of cell extracts suggests that BLM is not made in some Bloom's individuals (N.A. Ellis, unpubl.). Therefore, null mutations in human are apparently not incompatible with life. Our gene disruption resulted in integration of the phosphoglycerate kinase (PGK)-neo cassette upstream of the helicase homology region (Fig. 1A). Northern blot analysis of RNA isolated from a mutant fibroblast line indicates that the 4.4-kb Blm transcript has been eliminated (Fig. 2C; Ellis et al. 1995). This data, considered with embryo lethality, suggest that the BIm disruption results in a null allele.

Analysis of whole live mutant embryos and blood preparations indicates profound anemia prior to, and at the time of death. (Figs. 3, E and F, and 4A-D). The appearance of micronuclei indicates that defective cell division is occurring in red blood cells and their precursors (Fig. 4C-F). Defective mitosis should result both in appearance of defective cells and in their loss. These predictions are borne out in $B \mathrm{~mm}^{-/-}$blood cells, with the appearance of macrocytes and reduction of red blood cell numbers (Fig. 4A-D). In human red blood cells, inhibition of DNA synthesis results in anemia characterized by the appearance of macrocytes (Williams et al. 1972). Evidence for defective cell division in Blm mutant embryo blood cells is found as early as $9.5 \mathrm{dpc}$, when production of micronuclei exceeds that found in normal embryos (Fig. 4G). The time of death may reflect an increasing demand on embryo hematopoietic cell division to generate a sufficient blood supply for survival. Generally, anemia is not considered to be a part of the clinical profile in Bloom's patients (see introductory section). However, mild anemia of unknown origin has occasionally been described (German 1969).

In support of the defect in red blood cell proliferation being a potential cause of embryo death, we have been unable to find other defects in later stage mutant embryos. Morphological analysis of whole mutant embryos suggests that they exhibit normal developmental progression from 9.5 to $13.5 \mathrm{dpc}$ (Fig. 3A-D,F). Analysis of embryo sections shows numbers of mitotic figures and
BrdU-positive staining cells are both similar between normal and mutant later stage embryos (Fig. 6B; data not shown). Additionally, apoptosis is substantially decreased during later developmental stages relative to its peak earlier in development (Fig. 6A).

Excessive apoptosis in Blm mutants during early embryogenesis provides indirect evidence for a cellular response to DNA damage in vivo (Figs. 5, E and F, and 6A). The restriction of increased apoptosis to the embryonic ectoderm (epiblast) may be related to the high rate of cellular proliferation that occurs in this tissue type at this stage of development (Snow 1977). Mutation of Rad51 in mouse also results in increased apoptosis in the epiblast at $7.5 \mathrm{dpc}$ (Lim and Hasty 1996). In mouse embryos and vertebrate cells, loss of Rad51 function results in unrepaired double-stranded DNA breaks and chromosome loss (Lim and Hasty 1996; Sonoda et al. 1998).

We do not know what type of DNA damage results in apoptosis in $\mathrm{Blm}^{-/-}$embryos and this is under investigation. In contrast, formation of micronuclei in mutant blood cells provides direct evidence for DNA damage. Generally, micronuclei accumulate in cells exposed to carcinogens, or are found in cells from individuals with genetic predisposition to chromosome breakage such as BS (Heddle and Salamone 1981; Frorath et al. 1984; Rosin and German 1985). We speculate that induction of apoptosis in the epiblast and appearance of micronuclei in red blood cells and their precursors reflect a similar defect occurring during division of mutant cells.

We have shown that MEF cultures obtained from mutant embryos exhibit limited proliferation relative to those obtained from normal embryos (Fig. 7A). Retarded growth of primary mutant MEFs might be a direct result of a perturbation in DNA synthesis. However, the slow growth properties of mutant MEFs disappear when cultures pass through crisis, and mutant cell lines proliferate at rates that are comparable with normal control cell lines (Fig. 7B). This suggests that for cells with normal growth control constraints, slow growth may be a cellular response to an intrinsic defect. Likewise, removal of normal growth control through progression to immortality may abolish the cellular response to loss of Blm function and result in the ability of mutant cells to proliferate rapidly. In this regard, immortal $\mathrm{Blm}^{-/-}$cells have an inherent ability to divide with normal cell generation times. The possibility that the postcrisis mutant lines are defective in checkpoint control is currently being investigated. The increase in numbers of SCEs in Blm mutant versus control cell lines reflects genomic insta- 
bility in vitro (Fig. 8A,B; Table 2). Genomic instability may be the cause of the cellular response exhibited by primary Blm mutant cultures.

Physiological characteristics of $B \mathrm{~mm}^{-/-}$embryos and MEFs provide strong evidence that our BS mouse knockout model recapitulates various aspects of the human disease. To this end, we correlate four known features of the human disease phenotype with characteristics of mutant embryos and MEFs: (1) Small size of embryos and Bloom's newborn, (2) increased numbers of micronuclei in embryo blood cells and Bloom's epithelial cells, (3) slow growth in culture of embryo and Bloom's fibroblasts, and (4) high numbers of SCEs in cultured embryo fibroblasts and Bloom's cells. These data show that mutation of $B L M$ in human is sufficient to cause various aspects of the human disorder.

In addition, our finding of excessive apoptosis during early embryogenesis in Blm mutants is novel, because increased programmed cell death has not been described in BS. The possibility exists that small size exhibited in Bloom's newborn is also caused by a similar mechanism during fetal development.

\section{Materials and methods}

Isolation of murine Blm genomic and cDNA clones and construction of a targeting vector

A 477-bp mouse Blm fragment that corresponded to a region 5' to the helicase homology domain of the human cDNA sequence (Ellis et al. 1995) was obtained from mouse spleen cDNA by PCR. The fragment was amplified with sense (5'-GGCTCATTGTGGAGATACAGGCCTGATTCA-3') and antisense (5'AGGCAGCTGTGGAAGATTTGCTGGCTGCTA-3') oligonucleotides to the human sequence that spanned nucleotides 1347-1824 of the BLM cDNA (Ellis et al. 1995). Reactions were performed with Vent polymerase (New England Biolabs) in buffer and reaction components supplied by the manufacturer. Denaturation at $100^{\circ} \mathrm{C}$ for $5 \mathrm{~min}$ was followed by 35 cycles of $100^{\circ} \mathrm{C}$ for $1.5 \mathrm{~min}, 60^{\circ} \mathrm{C}$ for $2 \mathrm{~min}$, and $72^{\circ} \mathrm{C}$ for $3 \mathrm{~min}$. The reaction product was cloned into SmaI-digested Bluescript vector (Stratagene) and sequenced by standard protocols (Sambrook et al. 1989). Sequence analysis of the $0.48-\mathrm{kb}$ insert showed an overall homology of $78 \%$ between the mouse and human sequences (data not shown). The PCR DNA fragment was used as a probe to screen mouse 129/SvJ genomic (Stratagene) and NIH$3 \mathrm{~T} 3$ cDNA (a gift of Ari Elson, Weizmann Institute, Rehovot, Israel) libraries. Sequence analysis of a 1.1-kb NIH-3T3 cDNA clone showed that it was $77 \%$ homologous to a region spanning nucleotide residues 777-1844 in the human sequence (data not shown). The cDNA fragment designated clone P-1 was used to localize corresponding coding regions on a $15-\mathrm{kb}$ genomic clone designated $4-3 \mathrm{~B}$, as well as to establish the direction of transcription. The relative alignments of common coding regions present in human BLM cDNA, P-1 cDNA, and genomic clone $4-3 \mathrm{~B}$ are shown in Figure 1A. To generate the targeting construct, a 5' 4.0-kb EcoRI fragment was subcloned into the EcoRI site of pPNT (Tybulewicz et al. 1991), and the resulting plasmid was linearized by NotI and XhoI and ligated to a 3' 3.0-kb Bluescript HindIII fragment that had been modified by sequential digestion with ClaI, self-ligation of the resulting vector backbone, and redigestion with NotI and XhoI, which cleaved flanking polylinker sites. The final targeting vector designated
pPNT-11/4, is shown in Figure 1A and places the direction of transcription of the PGK-neo cassette opposite to that of the Blm gene.

\section{Chromosome localization of $\mathrm{Blm} c D N A$}

Radiolabeled P-1 clone cDNA was used to map Blm by Southern analysis of two genetic crosses: (NFS/N or C58/J $\times$ Mus musculus) $\times$ M. musculus (Kozak et al. 1990), (NFS $/ \mathrm{N} \times M$. spretus) $\times M$. spretus and $(\mathrm{NFS} / \mathrm{N} \times M$. spretus $) \times \mathrm{C} 58 / \mathrm{J}($ Adamson et al. 1991). P-1 identified HindIII fragments of 6.5 and 2.9 $\mathrm{kb}$ in $M$. spretus and 7.4 and $3.5 \mathrm{~kb}$ in NFS/N by Southern blot analysis. PVuII produced NFS/N fragments of 6.6 and $1.7 \mathrm{~kb}$ and fragments of 9.1 and $1.7 \mathrm{~kb}$ in $M$. spretus (data not shown). DNAs from the progeny of these crosses have been typed for $>1200$ markers that map to all 19 autosomes and the X chromosome including the Chr 7 markers Agc (aggrecan) and Tyr (tyrosinase) typed as described previously (Watanabe et al. 1994). Data were stored and analyzed by the LOCUS program. Percent recombination and s.E. between specific loci were calculated from the number of recombinants (Green et al. 1981). Loci were ordered by minimizing the number of recombinants.

Homologous recombination in ES cells and generation of germ-line chimeras

TC1 129/SvEv ES cells (Deng et al. 1996), were electroporated with NotI linearized pPNT-11 and selected with G418 and FIAU. Cell culture, electroporation, and selection of ES cells was carried out as described (Deng et al. 1994). ES cell colonies that were resistant to both G418 and FIAU were picked, propagated in 24- and 6-well dishes, and genomic DNA was prepared as described (Deng et al. 1994). Clone genomic DNA was subjected to digestion with BamHI, followed by Southern analysis by use of a probe $5^{\prime}$ to the EcoRI arm of pPNT-11/4. This fragment was derived from an internal region between BamHI and EcoRI sites present in clone 4-3B (Fig. 1A). Evaluation of 93 independent clones revealed one clone that had been correctly targeted. Cells from the targeted clone were microinjected into C57BL/J6 blastocysts followed by transfer into pseudopregnant Swiss Webster (Taconic) foster mothers and allowed to develop to term. High-grade agouti chimeras were mated to NIH Black Swiss females (Taconic). Germ-line transmission of the mutated $B 1 \mathrm{~m}$ allele was predicted by appearance of the agouti coat color in the $\mathrm{F}_{1}$ offspring, and this was confirmed by Southern blot analysis.

\section{RNA blot analysis}

Total RNA was isolated from either proliferating postcrisis MEF cell lines, developmentally staged wild-type embryos, or tissues from 2-month-old FVB (Taconic) mice by use of RNA STAT-60 (Tel-Test), on the basis of the manufacturer's protocol. Poly(A) RNA prepared from $250 \mathrm{mg}$ per sample of total RNA (Boehringer Mannheim) was electrophoresed in formaldehyde agarose. Membrane treatment, hybridization, and autoradiography with ${ }^{32} \mathrm{P}$-labeled P-1 probe was performed according to the manufacturer's directions (New England Nuclear).

\section{Embryo histology}

Embryos from heterozygous matings (noon on the day of appearance of the vaginal plug is defined as $0.5 \mathrm{dpc}$ ) were genotyped by PCR assay. The positions of the PCR primers are in- 
dicated in Figure 1A: A, 5'-CACTGAGGAATGTTTACCCACCACC-3'; B, 5'-GCAGCCTCTGTTCCACATACACTTC-3'; C, 5'-CCCAGTCATCATCTTCATCATCATC-3'. Genotype of 9.5- to 13.5-dpc embryos was on genomic DNA from yolk sacs dissected away from maternal material. Reactions were performed with Taq polymerase (Boehringer Mannheim) with simultaneous addition of the three primers in buffer and reaction components supplied by the manufacturer. Denaturation at $95^{\circ} \mathrm{C}$ for $5 \mathrm{~min}$ was followed by 35 cycles of $94^{\circ} \mathrm{C}$ for $0.5 \mathrm{~min}$, $60^{\circ} \mathrm{C}$ for $1 \mathrm{~min}$, and $72^{\circ} \mathrm{C}$ for $2 \mathrm{~min}$. Reaction products were electrophoresed in $1.5 \%$ agarose, product $\mathrm{A}-\mathrm{C}$, wild-type allele: $320 \mathrm{bp}$; product A-B, mutant allele: $190 \mathrm{bp}$. Whole embryos were washed in PBS and fixed in $4 \%$ paraformaldehyde/PBS overnight at $4^{\circ} \mathrm{C}$. Following PBS washes, embryos were dehydrated in ascending alcohol to $100 \%$, treated in xylenes and embedded in paraffin. Sagittal sections 5-microns thick were produced on a microtome and transferred to microscope slides. Histology on sections was by removal of wax in xylenes, rehydration of tissue in descending alcohol, and wash in water. For morphological analysis and scoring of apoptotic and mitotic figures, embryo sections were stained by the Feulgen reaction (Rosin and German 1985). Multiple washes in distilled water were substituted for sulfite washes (Demalsy and Callebaut 1967). Schiff's reagent was pararosaniline (Sigma). Slides were then dehydrated with ascending alcohol to $85 \%$, counterstained in $0.1 \%$ fast green (Fisher) in 95\% ethanol, treated in $100 \%$ alcohol, xylenes, and mounted with a coverslip by use of ProTexx (Baxter) mounting medium. For 6.0- to 8.0-dpc embryos, dissected decidua were treated in a similar manner to whole embryos (above). Genotypes were determined with peripheral embryo sections as described previously (Zeitlin et al. 1995). End labeling of nuclear DNA fragments with terminal deoxynucleotidyl transferase (TdT) was performed similarly as described (Gavrieli et al. 1992). Briefly, 7.5-dpc embryo sections were incubated in TUNEL reagent (ApopTag, Oncor), followed by addition of antidigoxigenin-peroxidase antibody conjugate. Color development was with VIP substrate (Vector Laboratories) followed by counterstain with methyl green.

\section{Micronucleus assay of red blood cells}

Micronucleus frequency in nucleated red blood cells and their precursors was determined on embryo sections stained by the Feulgen reaction and fast green (as described above). Criteria for scoring micronuclei were followed and have been published (Countryman and Heddle 1976).

\section{Cell proliferation assay}

Cell proliferation and maximal cell density determinations of primary MEFs were carried out in a similar manner to that described previously (Barlow et al. 1996). Briefly, the heart and liver were removed from 12.5- or 13.5-dpc embryos, the embryo head was retained for genotype analysis, and the remainder of the embryo disaggregated in plating medium with a P1000 pipettor. Single-cell suspensions were plated out in DMEM supplemented with $10 \%$ fetal calf serum, $2 \mathrm{~mm}$ glutamine, 100 $\mathrm{U} / \mathrm{ml}$ penicillin, and $100 \mu \mathrm{g} / \mathrm{ml}$ streptomycin. Cells were passaged by splitting at a dilution of 1:4 at confluency. For proliferation assay on primary cultures, $4.0 \times 10^{4}$ passage 2 cells were innoculated into duplicate $35 \mathrm{~mm}$ wells and counted every 24 or $48 \mathrm{hr}$ with a hemacytometer. Media change was on days cells were counted, and cultures were maintained up to 2 weeks. Cell lines were derived from cultures that had spontaneously recovered from crisis after being maintained in culture dishes for periods of 2-4 weeks. Lines were established from postcrisis dishes by passage at 1:4 dilution. Cell proliferation assay on immortal lines was carried out essentially as for primary fibroblasts, except that cell-seeding density was $3.0 \times 10^{4}$ per $35 \mathrm{~mm}$ well.

\section{SCE assay}

Analysis of SCEs in metaphase chromosomes was performed essentially as described (German and Alhadeff 1994). Metaphases that exhibited differential staining of sister chromatids in all chromosomes were photographed with Ektachrome 160T slide film (Kodak) with a Zeiss Axioskop microscope equipped with a camera and a $100 \times$ objective. Slides of metaphases were scanned with a slidescanner (SprintScan35) and stored on optical disks using Adobe photoshop computer software. Computer printouts of metaphase images were scored manually for SCEs and chromosome number.

\section{Acknowledgments}

We thank Debra Bader for the gift of adult mouse organ RNA. We also thank Tamar Enoch, Elspeth Stewart, Mark Bedford, Kevin Fitzgerald, Tim Lane, and Yaoqi Wang for helpful discussions and comments on the manuscript. N.C. is supported by the Leukemia Society of America fellowship no. 5584-98.

The publication costs of this article were defrayed in part by payment of page charges. This article must therefore be hereby marked 'advertisement' in accordance with 18 USC section 1734 solely to indicate this fact.

\section{References}

Adamson, M.C., J. Silver, and C.A. Kozak. 1991. The mouse homolog of the Gibbon ape leukemia virus receptor: Genetic mapping and a possible receptor function in rodents. Virology 183: 778-781.

Arlett, C.F. and A.R Lehmann. 1978. Human disorders showing increased sensitivity to the induction of genetic damage. Annu. Rev. Genet. 12: 95-115.

Barlow, C., S. Hirosune, R. Paylor, M. Liyanage, M. Eckhaus, F. Collins, Y. Shiloh, J.N. Crawley, T. Ried, D. Tagle, and A. Wynshaw-Boris. 1996. Atm-deficient mice: A paradigm of ataxia telangiectasia. Cell 86: 159-171.

Campisi, J. 1996. Replicative senescence: An old lives' tale? Cell 84: 497-500.

Chaganti, R.S.K., S. Schonberg, and J. German. 1974. A manyfold increase in sister chromatid exchanges in Bloom's syndrome lymphocytes. Proc. Nat1. Acad. Sci. 71: 4508-4512.

Countryman, P.I. and J.A. Heddle. 1976. The production of micronuclei from chromosome aberrations in irradiated cultures of human lymphocytes. Mutat. Res. 41: 321-332.

Demalsy, P. and M. Callebaut. 1967. Plain water as a rinsing reagent preferable to sulfurous acid after the Feulgen nucleal reaction. Stain Technol. 42: 133-136.

Deng, C., A. Wynshaw-Boris, M.M. Shen, C. Daugherty, D. Ornitz, and P. Leder. 1994. Murine FGFR-1 is required for early post-implantation growth and axial organization. Genes \& Dev. 8: 3045-3057.

Deng, C., A. Wynshaw-Boris, A. Kuo, F. Zhou, and P. Leder. 1996. Fibroblast growth receptor 3 is a negative regulator of bone growth. Cell 84: 911-921.

Ellis, N.A., J. Groden, T.-Z. Ye, J. Straughen, D.J. Lennon, S. Ciocci, M. Proytcheva, and J. German. 1995. The Bloom's syndrome gene product is homologous to RecQ helicases. Cell 83: 655-666. 
Frorath, B., U. Schmidt-Preuss, U. Steimers, M. Zöllner, and H.W. Rüdigner. 1984. Heterozygous carriers for Bloom syndrome exhibit a spontaneously increased micronucleus formation in cultured fibroblasts. Hum. Genet. 67: 52-55.

Gangloff, S., J.P. McDonald, C. Bendixen, L. Arthur, and R. Rothstein. 1994. The yeast type I topoisomerase Top3 interacts with Sgs1, a DNA helicase homolog: A potential eukaryotic reverse gyrase. Mol. Cell. Biol. 14: 8391-8398.

Gavrieli, Y., Y. Sherman, and S.A. Ben-Sasson. 1992. Identification of programmed cell death in situ via specific labeling of nuclear fragmentation. J. Cell Biol. 119: 493-501.

German, J. 1969. Bloom's syndrome. I. Genetical and clinical observations in the first twenty-seven patients. Am. J. Hum. Genet. 21: 196-227.

- 1993. Bloom syndrome: A mendelian prototype of somatic mutational disease. Medicine 72: 393-406.

- 1997. Bloom's syndrome. XX. The first 100 cancers. Cancer Genet. Cytogenet. 93: 100-106.

German, J. and B. Alhadeff. 1994. In Current protocols: Current protocols in human genetics (ed. N.C. Dracopoli, J.L. Haines, B.R. Korf, D.T. Moir, C.C. Morton, C.E. Seidman, J.G. Seidman, and D.R. Smith), section 8.6, vol. 1. Wiley and Sons, New York, NY.

Giannelli, F., P.F. Benson, S.A. Pawsey, and P.E. Polani. 1977. Ultraviolet light sensitivity and delayed DNA-chain maturation in Bloom's syndrome fibroblasts. Nature 265: 466469.

Gray, M.D., J.-C. Shen, A.S. Kamath-Loeb, A. Blank, B.L. Sopher, G.M. Martin, J. Oshima, and L.A. Loeb. 1997. The Werner syndrome protein is a DNA helicase. Nature Genet. 17: 100-103.

Green, E.L. 1981. Genetics and probability in animal breeding experiments. Oxford University Press, New York, NY.

Groden, J. and J. German 1992. Bloom's syndrome XVIII. Hypermutability at a tandem-repeat locus. Hum. Genet. 90: $360-367$.

Groden, J., Y. Nakamura, and J. German. 1990. Molecular evidence that homologous recombination occurs in proliferating human somatic cells. Proc. Natl. Acad. Sci. 87: 4315-4319.

Heartlein, M.W., H. Tsuii, and S.A. Latt. 1987. 5-Bromodeoxyuridine-dependent increase in sister chromatid exchange formation in Bloom's syndrome is associated with reduction in topoisomerase II activity. Exp. Cell Res. 169: 245-254.

Heddle, J.A. and M.F. Salamone. 1981. The micronucleus assay I. In vivo. In Short term tests for chemical carcinogens (ed. H.F. Stich and R.H.C. San), pp. 243-249. Springer, New York, NY.

Karow, J.K., R.K. Chakraverty, and I.D. Hickson 1997. The Bloom's syndrome gene product is a $3^{\prime}$ to $5^{\prime}$ DNA helicase. J. Biol. Chem. 272: 30611-30614.

Kozak, C.A., M. Peyser, M. Krall, T.M. Mariano, C.S. Kumar, S. Pestka, and B.A. Mock. 1990. Molecular genetic markers spanning mouse chromosome 10. Genomics 8: 519-524.

Kyoizumi, S., N. Nakamura, H. Takebe, K. Tatsumi, J. German, and M. Akiyama. 1989. Frequency of variant erythrocytes at the glycophorin-A locus in two Bloom's syndrome patients. Mutat. Res. 214: 215-222.

Langlois, R.G., W.L. Bigbee, R.H. Jensen, and J. German. 1989. Evidence for increased in vivo mutation and somatic recombination in Bloom's syndrome. Proc. Natl. Acad. Sci. 86: $670-674$.

Lim, D.-S. and P. Hasty. 1996. A mutation in mouse rad51 results in an early embryonic lethal that is suppressed by a mutation in p53. Mol. Cell. Biol. 16: 7133-7143.

Lu, J., J.R. Mullen, S.J. Brill, S. Kleff, A.M. Romeo, and R. Sternglanz. 1996. Human homologues of yeast helicase. Nature
383: 678-679.

Ray, J.H. and J. German. 1983. The cytogenetics of the 'chromosome-breakage syndromes.' In Chromosome mutation and neoplasia (ed. J. German), pp. 553-577. Alan R. Liss, New York, NY.

Rosin, M.P. and J. German. 1985. Evidence for chromosome instability in vivo in Bloom syndrome: Increased numbers of micronuclei in exfoliated cells. Hum. Genet. 71: 187-191.

Sambrook, J., E.F. Fritsch, and T. Maniatis. 1989. Molecular cloning. A laboratory manual, 2nd ed., Cold Spring Harbor Laboratory, Cold Spring Harbor, NY.

Snow, M.H.L. 1977. Gastrulation in the mouse: Growth and regionalization of the epiblast. J. Embryol. Exp. Morphol. 42: 293-303.

Sonoda, E., M.S. Saseki, J.-M. Buerstedde, O. Bezzubova, A. Shinohara, O. Hideyuki, M. Takata, Y. Yamaguchi-Iwai, and S. Takeda. 1998. Rad51-deficient vertebrate cells accumulate chromosomal breaks prior to cell death. EMBO J. 17: 598608.

Stewart, E., C.R. Chapman, F. Al-Khodairy, A.M. Carr, and T.

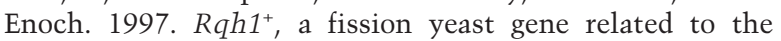
Bloom's and Werner's syndrome genes, is required for reversible S phase arrest. EMBO J. 16: 2682-2692.

Therman, E. and M. Susman 1993. Human chromosomes, structure, behavior and effects. Chapters 11 and 15. 3rd Ed., Springer-Verlag, New York, NY.

Todaro, G.J. and H. Green. 1963. Quantitative studies of the growth of mouse embryo cells in culture and their development into established lines. J. Cell Biol. 17: 299-313.

Tybulewicz, V.L., C.E. Crawford, P.K. Jackson, R.T. Bronson, and R.C. Mulligan. 1991. Neonatal lethality and lymphopenia in mice with a homozygous disruption of the $c$-abl protooncogene. Cell 65: 1153-1163.

Vijayalaxmi, H.J. Evans, J.H. Ray, and J. German. 1983. Bloom's syndrome: Evidence for an increased mutation frequency in vivo. Science 221: 851-853.

Warren, S.T., R.A. Schultz, C.-C. Chang, M.H. Wade, and J.E. Trosko. 1981. Elevated spontaneous mutation rate in Bloom syndrome fibroblasts. Proc. Natl. Acad. Sci. 78: 3133-3137.

Watanabe, H., K. Kimata, S. Line, D. Strong, L.-Y. Gao, C.A. Kozak, and Y. Yamada. 1994. Mouse cartilage matrix deficiency $(\mathrm{cmd})$ caused by a $7 \mathrm{bp}$ deletion in the aggrecan gene. Nature Genet. 7: 154-157.

Watt, P.M. and I.D. Hickson. 1996. Genome instability: Failure to unwind causes cancer. Curr. Biol. 6: 265-267.

Watt, P.M., E.J. Louis, T.H. Borts, and I.D. Hickson. 1995. Sgs1: A eukaryotic homolog of E. coli RecQ that interacts with topoisomerase II in vivo and is required for faithful chromosome segregation. Cell 81: 253-260.

Watt, P.M., I.D. Hickson, R.H. Borts, and E.J. Louis. 1996. SGS1, a homologue of the Bloom's and Werner's syndrome genes, is required for maintenance of genome stability in Saccharomyces cerevisiae. Genetics 144: 935-945.

Williams, W.J., E. Beutler, A.J. Erslev, and R.W. Rundles. 1972. Hematology. pp. 251-252. McGraw-Hill, New York, NY.

Willis, A.E. and T. Lindahl. 1987. DNA ligase I deficiency in Bloom's syndrome. Nature 325: 355-357.

Yu, C.E., J. Oshima, Y.H. Fu, E.M. Wijsman, F. Hisama, R. Alish, S. Matthews, J. Nakura, T. Miki, S. Ouais, G.M. Martin, J. Mulligan, and G.D. Schellenberg. 1996. Positional cloning of the Werner's syndrome gene. Science 272: 258262.

Zeitlin, S., J.-P. Liu, D.L. Chapman, V.E. Papaioannou, and A. Efstratiadis. 1995. Increased apoptosis and early embryonic lethality in mice nullizygous for the Huntington's disease gene homologue. Nat. Genet. 11: 155-163. 


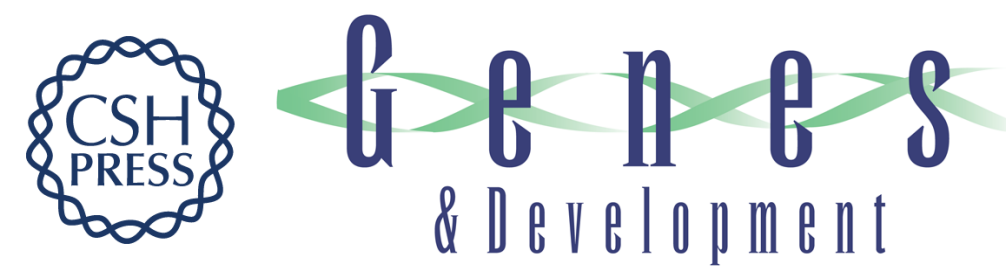

\section{Stage-specific apoptosis, developmental delay, and embryonic lethality in mice homozygous for a targeted disruption in the murine Bloom's syndrome gene}

Nicholas Chester, Frank Kuo, Christine Kozak, et al.

Genes Dev. 1998, 12:

Access the most recent version at doi:10.1101/gad.12.21.3382

References This article cites 42 articles, 15 of which can be accessed free at:

http://genesdev.cshlp.org/content/12/21/3382.full.html\#ref-list-1

License

Email Alerting Receive free email alerts when new articles cite this article - sign up in the box at the top Service right corner of the article or click here.

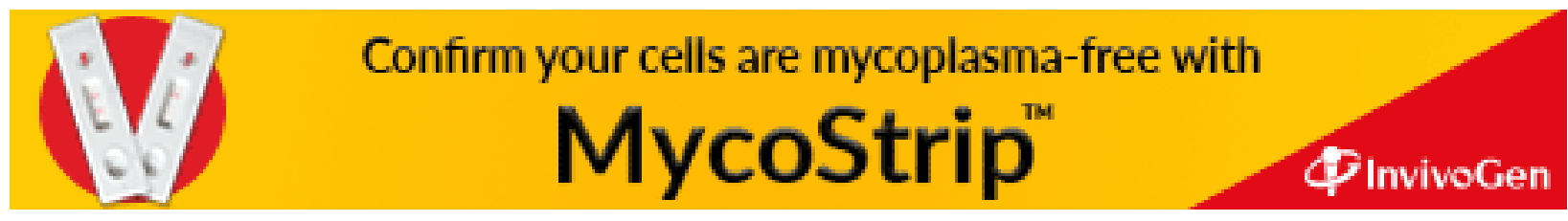

